Retraction

\title{
Retracted: The Parenteral Vitamin C Improves Sepsis and Sepsis- Induced Multiple Organ Dysfunction Syndrome via Preventing Cellular Immunosuppression
}

\author{
Mediators of Inflammation \\ Received 4 July 2020; Accepted 14 July 2020; Published 4 September 2020 \\ Copyright (C) 2020 Mediators of Inflammation. This is an open access article distributed under the Creative Commons Attribution \\ License, which permits unrestricted use, distribution, and reproduction in any medium, provided the original work is \\ properly cited.
}

Mediators of Inflammation has retracted the article titled "The Parenteral Vitamin C Improves Sepsis and SepsisInduced Multiple Organ Dysfunction Syndrome via Preventing Cellular Immunosuppression" [1] due to figure duplication between articles by the same authors.

Figure duplication concerns were raised to our attention and then noted on PubPeer [2]. A reassessment of the article concluded that a number of panels in Figure 2(g) of [1] were duplicates of panels in Figure 1 of [3]. Duplications were also identified in another article [4], where the fourth panel of Figure 5(e) in [1] duplicates the third panel of Figure $8(\mathrm{~b})$ in [4].

The authors did not provide a satisfactory response and the article is therefore being retracted with the agreement of the Chief Editor. The authors do not agree to the retraction.

\section{References}

[1] Y.-L. Gao, B. Lu, J.-H. Zhai et al., “The Parenteral Vitamin C Improves Sepsis and Sepsis-Induced Multiple Organ Dysfunction Syndrome via Preventing Cellular Immunosuppression," Mediators of Inflammation, vol. 2017, 12 pages, 2017.

[2] PubPeer 2018, https://pubpeer.com/publications/5EB78957 D481A43893D38764FB3118.

[3] Y.-L. Gao, Y.-F. Chai, A.-L. Qi et al., "Neuropilin-1highCD4 +CD25+ Regulatory T Cells Exhibit Primary Negative Immunoregulation in Sepsis," Mediators of Inflammation, vol. 2016, Article ID 7132158, 11 pages, 2016.

[4] Y.-L. Gao, M.-M. Yu, S.-T. Shou et al., "Tuftsin prevents the negative immunoregulation of neuropilin-1highCD4+CD25 +regulatory T cells and improves survival rate in septic mice," Oncotarget, vol. 7, no. 49, pp. 81791-81805, 2016. 